\title{
O PROCESSO DE DECISÃO \\ RELACIONADO À IMPLANTAÇÃO \\ DO IFRS 9 EM UMA INSTITUIÇÃO FINANCEIRA
}

\section{Ana Maria Roux Valentini César}

Professora do Programa de Pós-Graduação em Controladoria e Finanças Empresariais da Universidade Presbiteriana Mackenzie. E-mail:anamaria.cesar@mackenzie.br Ailton Lopes Júnior
Graduado em Ciências Contábeis pela Universidade Presbiteriana Mackenzie, em 2017.
Analista contábil na divisão OTC \& Broker Dealer do grupo ED\&F Man Capital Markets.
E-mail: juniorlopes05@gmail.com

Kaique Henrique Ferreira

Graduado em Ciências Contábeis pela Universidade Presbiteriana Mackenzie. Contador na empresa Valle Sistemas de Gestão Ltda. E-mail: kaiquehenriqueferreira@bol.com.br

\section{Marina Revoredo Rodrigues}

Graduada em Ciências Contábeis pela Universidade Presbiteriana Mackenzie. Analista contábil na área de Gestão Contábil de Crédito do Banco Safra S/A. 
O PROCESSO DE DECISÃO RELACIONADO À IMPLANTAÇÃO DO IFRS 9 EM UMA INSTITUIÇÃO FINANCEIRA

\section{RESUMO}

Este artigo tem por objetivo identificar, em uma instituição financeira privada, quais são as decisões críticas referentes à estruturação do ambiente contábil para a implantação do IFRS 9 e quais são as competências requeridas dos profissionais envolvidos nesse processo. O trabalho foi desenvolvido a partir da aplicação de entrevistas com funcionários participantes do processo de tomada de decisão na implantação do IFRS 9. Para o tratamento dos dados, foi aplicada a análise de conteúdo, constatando-se que as decisões críticas na implantação da norma estão relacionadas às mudanças dos estágios de estimativas de perdas, alteração da classificação dos instrumentos financeiros em estoque e desenvolvimento de metodologias para classificação de novos instrumentos financeiros. Constatou-se que, entre as competências requeridas dos profissionais envolvidos nesse processo, destacam-se a capacidade de bons relacionamentos interpessoais, a curiosidade na busca de novos conhecimentos, a capacidade analítica e um entendimento amplo do negócio. Este trabalho possui implicações práticas para organizações adotantes das normas internacionais de contabilidade, possibilitando a compreensão das principais decisões envolvidas no processo de implantação da norma IFRS 9, bem como as competências apontadas como essenciais por esses profissionais. Ademais, este artigo busca olhar para a norma IFRS 9 por uma perspectiva original, considerando a importância dos julgamentos contábeis, que derivam do perfil de decisão dos profissionais atuantes nessa área.

\section{PALAVRAS-CHAVE}

IFRS 9. Tomada de decisão. Julgamento. 


\section{INTRODUÇÃO}

A convergência dos procedimentos contábeis da normatização brasileira para a internacional, com as discussões sobre as normas fundamentadas em regras ou em princípios, são assuntos relevantes e contemporâneos. As novas normas estabelecidas pelo IASB (International Accounting Standards Board - Conselho de Normas Internacionais de Contabilidade) possuem foco no desempenho da entidade econômica, por meio das informações financeiras consolidadas.

Em um contexto de globalização, é imprescindível que as empresas incorporem os novos conceitos apresentados pelo IFRS (International Financial Reporting Standards Conjunto de Normas Internacionais de Contabilidade), de forma a participar ativamente do mercado financeiro internacional.

A implantação do IFRS, contudo, é um processo de alta complexidade e demanda uma mudança de paradigma, uma vez que tais pronunciamentos requerem dos gestores, contadores e auditores o exercício da tomada de decisão em escala substancialmente maior que anteriormente sua implantação (MAIA, 2012).

Conforme afirma Mintz (2011), o IFRS integra uma abordagem fundamentada muito mais em princípios contábeis do que em regras. De acordo com o sistema norteado por princípios, deve-se considerar a substância econômica dos dados financeiros e sua fidelidade de representação, a fim de fazer julgamentos profissionais acerca da utilidade da informação financeira.

Tais julgamentos contábeis estão presentes não somente nos procedimentos de implantação do IFRS, mas também no tratamento de eventos e transações pós-implantação. De acordo com Schmutte e Duncan (2009), os pronunciamentos contábeis propõem a estrutura geral das demonstrações financeiras. A classificação e a demonstração de transações e eventos específicos, entretanto, requerem elementos de julgamento. Isso inclui a determinação do nível de detalhe fornecido na divulgação de transações e eventos excepcionais. Vale citar que nem todas as transações e os eventos estão presentes no escopo de normas existentes; em algumas situações, os profissionais precisam aplicar julgamentos para identificar o princípio contábil implícito ou, por analogia, exceder uma norma existente para demonstrar tal situação. 
Como afirmam Schmutte e Duncan (2009), o julgamento profissional sempre foi um elemento crítico na contabilidade. A tendência das mudanças em pronunciamentos contábeis é que sejam fornecidas menos orientações específicas para uma maior utilização de julgamentos contábeis. Nesse contexto, os profissionais da contabilidade têm um papel fundamental no desenvolvimento do processo decisório.

Para Schmutte e Duncan (2009), os julgamentos contábeis podem se diferenciar por fatores como a experiência daquele que faz o julgamento e pelos objetivos individuais. Resultados positivos dependem essencialmente do conjunto de conhecimentos, habilidades e atitudes aplicados pelos indivíduos na tomada de decisão, ou seja, das competências dos profissionais da contabilidade, especialmente aquelas associadas aos processos de julgamento e decisão, essenciais para o sucesso das decisões no ambiente de IFRS.

A partir desse tema, este artigo apresenta como problema de pesquisa: quais são as decisões críticas referentes à estruturação do ambiente contábil para a implantação do IFRS 9 em instituições financeiras e quais são as competências requeridas para os profissionais envolvidos nesse processo?

Visando responder ao problema de pesquisa, tem-se como objetivo geral do artigo: identificar, em uma instituição financeira privada, quais são as decisões críticas referentes à estruturação do ambiente contábil para a implantação do IFRS 9 e quais são as competências requeridas para os profissionais envolvidos nesse processo. Como objetivos específicos, tem-se:

1) Identificar, em uma instituição financeira privada, quais são as decisões críticas referentes à estruturação do ambiente contábil para a implantação do IFRS 9.

2) Identificar quais são as competências requeridas dos profissionais envolvidos com o processo de implantação do IFRS 9.

O interesse pelo tema proposto surgiu - entre outros fatores - pela contemporaneidade do assunto, que afeta essencialmente as instituições financeiras em todos os países adotantes das normas internacionais. Os aspectos inerentes à implementação do IFRS 9 exigem atenção das empresas em relação às complexidades técnicas, aos impactos potenciais, aos prazos de implementação e à necessidade de investimentos consideráveis em sistemas e estrutura 
de controles. Esse processo de mudança requer que as empresas busquem informações e referências externas para corroborar o desenvolvimento das novas práticas contábeis.

Ademais, acentua-se a necessidade de que essas empresas tenham ciência dos riscos de tais processos e da importância da tomada de decisão e dos julgamentos contábeis, buscando discernir quais competências são imprescindíveis aos profissionais envolvidos no processo. Assim, este artigo contribui para a comunidade empresarial, especialmente às instituições financeiras, realçando aspectos que podem ser relevantes para a preparação de profissionais que atuem em empresas que seguem os padrões internacionais de contabilidade.

\section{REFERENCIAL TEÓRICO}

Apresenta-se, na primeira parte do referencial teórico, considerações gerais acerca do IFRS e da norma denominada IFRS 9; na segunda parte, apresentam-se os aspectos comportamentais relacionados às decisões de modo que se possa compreender o processo decisório no ambiente IFRS; na terceira parte, apresenta-se uma discussão sobre o conceito de competências.

\section{International Financial Reporting Standards 9 - Financial Instruments}

De acordo com Ramos (2014), o projeto IFRS 9 (International Financial Reporting Standards 9 - Financial Instruments) teve início em março de 2008 com a publicação pelo IASB do relatório "Discussion Paper: Reducing Complexity in Reporting Financial Instruments", que discutiu a necessidade de reduzir a complexidade do reporte dos instrumentos financeiros. Simultaneamente, o projeto foi motivado pelas preocupações acerca do reconhecimento tardio das perdas por redução do valor recuperável de ativos financeiros, por culpa da crise financeira da época.

Em 24 de julho de 2014, publicou-se pelo IASB a última versão da norma IFRS 9, concluindo as três fases do projeto iniciado em 2008: definição de novas regras de classificação e mensuração de ativos e passivos financeiros; definição da nova metodologia de reconhecimento das perdas por redução do valor recuperável de ativos financeiros; e a definição de melhorias nas regras de Hedge Accounting (RAMOS, 2014). 
Conforme exposto no texto do pronunciamento IFRS 9, seu objetivo é estabelecer princípios para o relatório financeiro de ativos financeiros e passivos financeiros, que devem apresentar informações pertinentes e úteis aos usuários de demonstrações contábeis para avaliação dos valores, época e incerteza dos fluxos de caixa futuros da entidade. A norma internacional IFRS 9 define novas regras de classificação, mensuração e apresentação dos instrumentos financeiros, em substituição à norma IAS 39 (International Accounting Standards). No Brasil, sua tradução foi publicada pelo Comitê de Pronunciamentos Contábeis como o Pronunciamento Técnico CPC 48 - Instrumentos Financeiros.

A seguir, serão expostos resumidamente os principais pontos da norma IFRS 9, que deverão impactar, sobretudo, as instituições financeiras em todos os países adotantes da norma, com base no texto emitido pela IASB, comparando pontos-chave das normas IFRS 9 e IAS 39.

\section{Reconhecimento de Instrumentos Financeiros}

A norma IFRS 9 manteve a opção pelo valor justo (fair value option) no momento do reconhecimento inicial do instrumento financeiro, se a sua aplicação eliminar ou reduzir significativamente um descasamento contábil no resultado. Manteve também as regras de desreconhecimento (retirada de ativo ou passivo reconhecido anteriormente do balanço patrimonial da entidade) dos ativos financeiros (IFRS Foundation; 2014).

De acordo com a norma, a entidade deve reconhecer um ativo financeiro ou um passivo financeiro em seu balanço patrimonial quando, e apenas quando, a entidade se tornar parte das disposições contratuais do instrumento. Em contrapartida, a entidade deve desreconhecer um ativo financeiro quando, e apenas quando, os direitos contratuais aos fluxos de caixa do ativo financeiro expirarem ou quando transferir o ativo financeiro e esta transferência se qualificar para desreconhecimento, de acordo com as definições da regulamentação.

\section{Classificação e mensuração}

Anteriormente, os instrumentos financeiros eram classificados em diversas categorias estabelecidas pela norma IAS 39, e os ativos financeiros possuíam quatro classificações: 
ativos ao valor justo por meio do resultado; investimentos mantidos até o vencimento; empréstimos e recebíveis; e ativos financeiros disponíveis para a venda. Os passivos financeiros eram classificados em: passivos ao valor justo por meio do resultado e passivos ao custo amortizado (RAMOS, 2014).

A nova norma internacional IFRS 9 contempla apenas três categorias de classificação e mensuração de ativos financeiros (para os passivos financeiros, as classificações da norma anterior foram mantidas). São elas: instrumentos financeiros ao custo amortizado; instrumentos financeiros ao valor justo por meio dos outros resultados abrangentes; e instrumentos financeiros ao valor justo por meio do resultado (RAMOS, 2014).

Para a classificação dos ativos financeiros, utilizam-se como base dois critérios-chave: o modelo de negócios da entidade para a gestão dos ativos financeiros; e as características de fluxo de caixa contratual do ativo financeiro (Ramos, 2014).

O diagrama da Figura 1 tem o objetivo de descrever o processo de classificação dos ativos financeiros de acordo com os critérios estabelecidos pela norma IFRS 9.

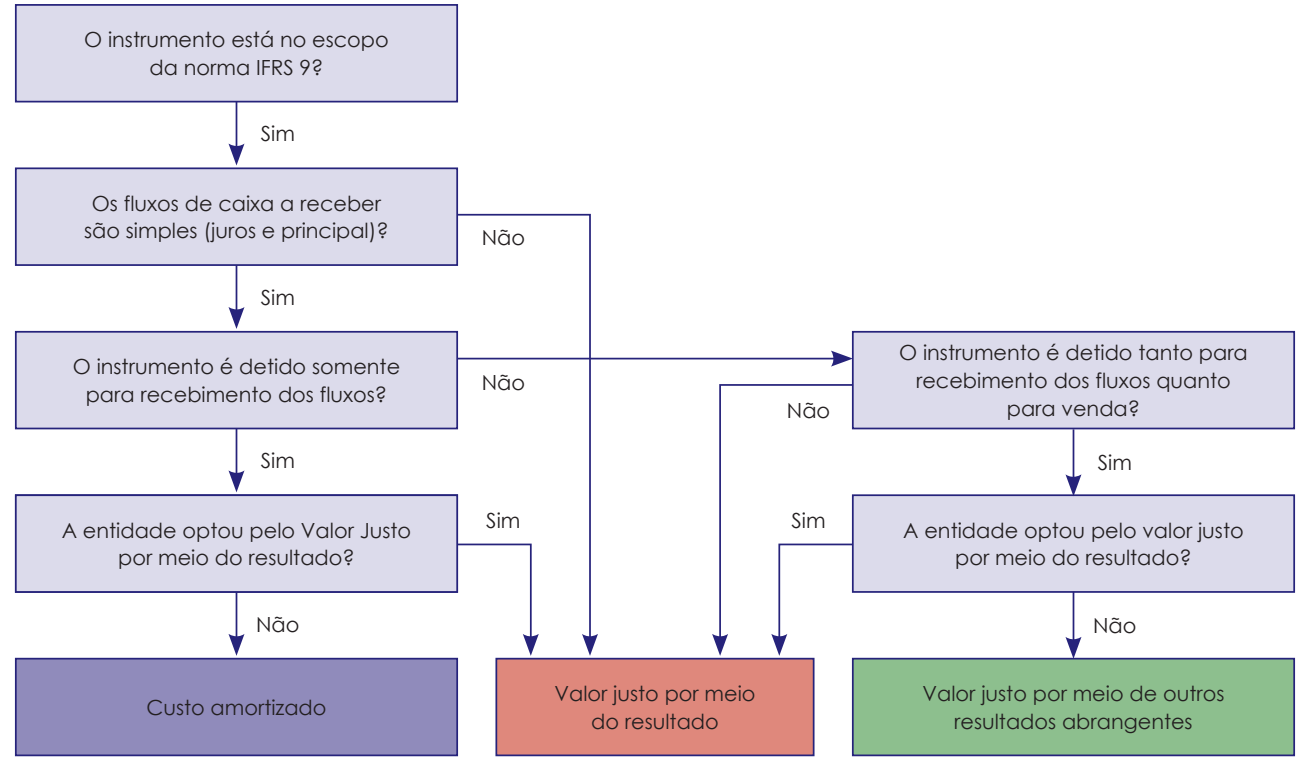

FIGURA 1 - Roteiro de classificação de ativos financeiros

Fonte: Adaptado de Ramos (2014). 
Conforme evidencia a norma, devem ser mensurados como custo amortizado todos os ativos financeiros mantidos dentro de modelos de negócio cujo objetivo seja manter ativos financeiros com o intuito de receber fluxos de caixa contratuais, e cujos termos contratuais originem, em datas especificadas, fluxos de caixa que constituam exclusivamente pagamentos de principal e juros sobre o valor do principal em aberto (instrumentos de dívida simples).

Para serem classificados como valor justo por meio de outros resultados abrangentes, os ativos financeiros devem ser mantidos dentro de modelo de negócios cujo objetivo seja atingido tanto pelo recebimento de fluxos de caixa contratuais quanto pela venda de ativos financeiros e, assim como no custo amortizado, devem ser caracterizados como instrumentos de dívida simples. Todos os ativos financeiros que não se enquadrarem nesses critérios de classificação descritos devem ser classificados e mensurados como valor justo por meio do resultado. Contudo, no reconhecimento inicial de um ativo financeiro, há a opção de designá-lo de modo irrevogável como mensurado ao valor justo por meio do resultado se isto puder eliminar ou reduzir significativamente um descasamento contábil.

Em relação à classificação e mensuração de passivos financeiros, a IFRS 9 mantém basicamente os critérios publicados na norma IAS 39, com exceção dos impactos das mudanças no risco de crédito da própria entidade; anteriormente contabilizados como resultado, em conformidade com a IFRS 9 passam a ser contabilizados em outros resultados abrangentes.

A norma afirma ser permitido à entidade reclassificar um ativo financeiro quando, e somente quando, a entidade mudar seu modelo de negócios para a gestão de ativos financeiros, devendo reclassificar todos os ativos financeiros afetados por esta mudança. Entretanto, a norma proíbe a entidade de reclassificar qualquer passivo financeiro (IFRS FOUNDATION, 2014).

\section{Redução ao valor recuperável}

A norma IFRS 9 substitui o modelo das perdas do valor recuperável de ativos financeiros com base em perdas históricas (incurred loss model) pelo modelo inspirado em perdas 
esperadas (expected loss model). O novo modelo aplica-se aos ativos financeiros não mensurados ao valor justo pelo resultado. Como elucida Ramos (2014), na crise do sistema financeiro de 2008, o reconhecimento atrasado das perdas em decorrência da redução do valor recuperável de instrumentos financeiros foi identificado como uma fraqueza nas normas IFRS existentes. Especificamente, o modelo existente no IAS 39 atrasa o reconhecimento de perdas até que haja evidência de um evento de perda incorrida, mesmo quando há evidência probabilística de perdas esperadas. O modelo de perdas esperadas deve evidenciar maiores níveis de provisão do que o modelo de perdas incorridas, devendo-se ajustar mais precisamente às efetivas perdas com operações de crédito e outros instrumentos.

O objetivo dos requisitos de redução ao valor recuperável é reconhecer perdas de crédito esperadas para todos os instrumentos financeiros para os quais houve aumentos significativos no risco de crédito desde o reconhecimento inicial, avaliados de forma individual ou coletiva, considerando todas as informações razoáveis e sustentáveis, incluindo informações prospectivas (RAMOS, 2014).

Para aplicar o princípio da perda esperada, a norma IFRS 9 descreve alguns componentes para estimativa das provisões de perdas esperadas nos ativos financeiros, sendo eles: identificar toda a informação razoável, suportável e relevante para formar a estimativa de perda para o futuro; identificar a gama de possíveis resultados considerando a probabilidade e razoabilidade desses resultados; e identificar valor do dinheiro no tempo.

Em cada data de relatório, a entidade deve mensurar a provisão para perdas de instrumento financeiro ao valor equivalente às perdas de crédito esperadas caso o risco de crédito desse instrumento financeiro tiver aumentado significativamente desde o reconhecimento inicial (IFRS FOUNDATION, 2014).

\section{Vigência e transição}

A norma IFRS 9 é de aplicação obrigatória para os exercícios iniciados após 1ำ de janeiro de 2018 e deverá ser, portanto, aplicada impreterivelmente pelas entidades que apresentem suas demonstrações financeiras em conformidade com as normas internacionais, 
nos exercícios iniciados a partir dessa data. Como consequência, em $1^{\underline{o}}$ de janeiro de 2018, a norma IFRS 9 substituirá a norma IAS 39 (RAMOS, 2014).

Dada a obrigatoriedade da implantação da norma, as empresas que seguem os padrões internacionais de contabilidade terão de realizar o processo de implementação dos novos conceitos apresentados. São procedimentos complexos que requerem tomadas de decisão críticas, podendo influenciar significativamente os resultados da empresa.

A norma IFRS 9 também exige julgamentos constantes no ambiente pós-implantação, no qual os profissionais devem se fundamentar nos princípios da norma para escolher a melhor alternativa. Desse modo, torna-se relevante o entendimento do processo decisório desses profissionais.

\section{processo decisório}

Segundo Bazerman (2014), o processo de tomada de decisão faz-se necessário quando, e apenas quando, há um problema a ser julgado e existirem uma ou mais alternativas para solucioná-lo. O autor explana que o termo julgamento refere-se aos aspectos cognitivos do processo de tomada de decisões.

A tomada de decisão pode ocorrer por meio de processos racionais (controlados) ou não racionais (automáticos). No contexto de decisão, a "não racionalidade" não se refere à irracionalidade, que é a perda da razoabilidade no argumento; antes, refere-se aos processos rápidos de decisão, que usam atalhos cognitivos e que são fundamentados em experiência prévia e aprendizagem, muitas vezes não conscientes ao sujeito (CAMERER; LOEWENSTEIN; PRELEC, 2005). Já os processos racionais (controlados) envolvem, de acordo com Bazerman (2014), seis etapas que os tomadores de decisão podem seguir, implícita ou explicitamente. Nesse processo, subentende-se que os indivíduos:

1) Definem o problema perfeitamente.

2) Identificam todos os critérios.

3) Ponderam com precisão todos os critérios segundo suas preferências;

4) Conhecem todas as alternativas relevantes; 
5) Avaliam com precisão cada alternativa com base em cada critério.

6) Calculam as alternativas com precisão e escolhem a de maior valor percebido.

Apesar da clara descrição dessas etapas, há tempos, os autores reconhecem que esse processo racional não é o processo usualmente aplicado quando as pessoas tomam decisões em seu dia a dia, seja no ambiente de trabalho, seja em sua vida pessoal; por exemplo, pessoas tendem a classificar seus ganhos e despesas em contas mentais, e não necessariamente transferem valor de uma dessas contas para outra, mesmo quando a transferência é vantajosa, como usar uma reserva de férias para amortizar uma conta cujo juro seja maior do que o ganho auferido pelo valor aplicado para as férias (THALER, 1999). Ele geralmente é acionado quando o risco da decisão é alto, quando o montante da perda (decorrente da possível efetivação do erro) é elevado e quando a situação sobre a qual se decide é considerada atípica, ou seja, fora do padrão habitual de decisão.

\section{Heurísticas e vieses}

Kahneman (2003) analisa os sistemas de decisão como um sistema binário, sendo o sistema 1 referente à decisão automática, e o sistema 2, à decisão racional. Para Kahneman (2003), o sistema 1 refere-se ao sistema que normalmente se denomina como decisão fundamentada na intuição; as decisões assim tomadas são rápidas, automáticas, sem esforço cognitivo e sensibilizam o domínio afetivo (emoções, motivações, drivers de ação). Ao contrário, o sistema 2 refere-se ao raciocínio mais lento, consciente, esforçado, explícito e lógico, que é expresso quando se fala, no dia a dia, "preciso parar para pensar", por exemplo.

Segundo Bazerman (2014), na maioria das situações do dia a dia, o sistema 1 é mais utilizado, pois, quanto mais ocupados e apressados os indivíduos estiverem, maior é a probabilidade de que utilizem o pensamento no sistema 1 . Todavia, esse sistema se apoia em atalhos cognitivos, as chamadas heurísticas, que são estratégias simplificadoras, ou regras práticas, ao tomar decisões (BAZERMAN, 2014). As quatro principais heurísticas abordadas neste trabalho são: 
1) Da disponibilidade.

2) Da representatividade.

3) O teste de hipótese positiva.

4) A heurística do afeto.

A heurística de disponibilidade é definida como o processo de julgamento conforme a facilidade com que as ocorrências vêm à mente (KAHNEMAN, 2012). Conforme Bazerman (2014), um evento que sensibilize emoções e que seja vívido, fácil de imaginar e específico, está mais disponível na memória do que um evento de natureza não emocional, brando, difícil de imaginar ou vago. A heurística da representatividade ocorre quando, ao fazer um julgamento sobre um indivíduo, objeto ou evento, as pessoas tendem a procurar peculiaridades que ele possa ter e que correspondam a estereótipos formados anteriormente.

Segundo Bazerman (2014), esse tipo de heurística é muito utilizado pelos administradores, pois, como exemplifica o autor (2014, p. 12), “[...] Se um gerente acha que os melhores vendedores provavelmente serão os extrovertidos [...] então favorecerá esse tipo de pessoa para seus cargos de vendas”. Analisando-se a heurística do teste de hipótese, observa-se que, ao testar a relação entre dois eventos (teste de hipótese), o sujeito tende a desconsiderar uma série de fatores que interferem na relação examinada, deixando de lado fatores que se liguem ao objeto.

As pessoas selecionam (com base em critérios que considera relevantes) dados para testar hipóteses. Sendo assim, só uma parte dos dados vinculados à hipótese são analisados, ocorrendo desta forma um julgamento equivocado (BAZERMAN, 2014). Em termos de heurística afetiva, Kahneman (2003) aponta que a maioria dos julgamentos são realizados com base em uma avaliação afetiva ou no estado emocional do decisor em relação ao problema a ser julgado; a influência afetiva sobre o julgamento e a decisão ocorre mesmo em situações nas quais haja qualquer raciocínio de nível mais alto, ou seja, de uso do sistema racional de decisão (KAHNEMAN, 2003).

Ainda que facilitem as decisões cotidianas, porque permitem decisões paralelas e rápidas, como "atalhos", as heurísticas acabam ocasionando erros de julgamento, deno- 
minados vieses, os quais possuem mais chances de ocorrerem no sistema 1 do que no sistema 2. As aplicações inapropriadas das heurísticas dificilmente são evitáveis. Muitas vezes, tomam-se decisões em contextos que são extremamente distintos, e podem ser empregados equivocadamente os mesmos processos decisórios utilizados com êxito no passado em um contexto completamente diferente no futuro, ocasionando vieses (KAHNEMAN; KLEIN, 2008).

A heurística de disponibilidade ocasiona os vieses (a) facilidade de lembrança e (b) recuperabilidade; a heurística de representatividade gera os vieses (c) insensibilidade aos Índices Básicos, (d) Insensibilidade ao tamanho da amostra, (e) interpretações erradas de chance, (f) regressão à média e (g) falácia da conjunção; a heurística do teste de hipótese positiva gera os vieses (h) de confirmação e (i) de previsão retrospectiva; e a heurística do afeto gera o viés (j) de influências motivacionais (BAZERMAN, 2014).

$\mathrm{O}$ viés da Facilidade de Lembrança (a) afirma que os indivíduos consideram que eventos mais facilmente recuperados pela memória, com base na visibilidade ou atualidade, são mais numerosos que eventos de igual frequência cujos exemplos são lembrados com menos facilidade. A Recuperabilidade (b) diz respeito à "avaliação que os indivíduos fazem da frequência de eventos, que sofre viés com base no modo como as estruturas de suas memórias afetam o processo de busca" (BAZERMAN, 2014). Deve-se lembrar aqui de que a memória é reconstrutiva, ou seja, quando se recupera uma informação, ela traz seus traços essenciais, não sua totalidade; assim, o que falta pode ser "inventado" (BADDELEY; ANDERSON; EYSENCK, 2011).

Segundo dados da Insensibilidade aos Índices Básicos (c), ao avaliar a probabilidade de eventos, indivíduos tendem a ignorar os índices básicos caso seja fornecida qualquer outra descrição informativa, mesmo que irrelevante; esse viés é especialmente interessante quando se avaliam situações de decisão em ambientes corporativos, pois o excesso de relatórios pode desviar o sujeito dos índices básicos. A Insensibilidade ao Tamanho da Amostra (d) revela que quando avaliam a confiabilidade de informações de amostras, indivíduos frequentemente falham na avaliação do papel do tamanho da amostra. Em outras palavras, não consideram se a amostra é ou não representativa do universo que está sendo analisado. 
O viés de Interpretações Erradas da Chance (e) afirma que os indivíduos esperam que uma sequência de dados gerada por um processo aleatório pareça “aleatória”, mesmo quando a série for muito curta para que essas expectativas sejam estatisticamente válidas. Isso significa, por exemplo, que se um indivíduo encontrou um preço mais barato em um supermercado nas compras que fez neste mês, que essa vantagem se manterá para sempre durante o ano (BAZERMAN, 2014).

A Regressão à Média (f) evidencia que as pessoas são propensas a ignorar o fato de que eventos extremos tendem a regredir à média em tentativas subsequentes (BAZERMAN, 2014, p. 86). O viés referente à Falácia da Conjunção (g) diz que as pessoas julgam erroneamente que "as conjunções - dois eventos ocorrendo concomitantemente - são mais prováveis do que um conjunto mais global de ocorrências do qual a conjunção é um subconjunto" (BAZERMAN, 2014, p. 86).

$\mathrm{O}$ viés de Confirmação (h) diz que os indivíduos procuram e interpretam evidências, de modo a dar suporte às conclusões que favoreceram no início (NICKERSON, 1998). Esse viés mostra que as pessoas tendem a ignorar informações que deem indícios de que o seu julgamento possa estar errado. A Previsão Retrospectiva (i) diz respeito aos indivíduos que rejeitam rapidamente, de forma retrospectiva, a possibilidade de que as coisas poderiam ocorrer de modo diferente (BAZERMAN, 2014). É como se as pessoas não pudessem lidar com o fato de que o presente poderia ter sido diferente se outras decisões tivessem sido tomadas no passado. Dessa forma, rever o passado não é uma possibilidade de aprendizagem.

As Influências Motivacionais ( $\mathrm{j}$ ) impactam as tomadas de decisão causadas por fatores como pressão emocional e a necessidade dos indivíduos de se verem de um modo positivo. Os indivíduos tendem a ver eventos do modo como gostariam que acontecessem, sendo influenciados por motivações e emoções que podem mudar de modo sistemático as decisões tomadas pelos mesmos (BAZERMAN, 2014).

$\mathrm{O}$ advento da norma IFRS 9 requer dos profissionais contábeis uma função de julgamento cotidiano mais intensa que outrora. Por causa desses fatores, as heurísticas se tornam mais frequentes na tomada de decisão fazendo que os profissionais corram o risco de cair nos vieses mais comuns. Sendo assim, torna-se pertinente reconhecer quais são as 
competências necessárias a esses julgamentos que, consequentemente, são valorizadas nesses profissionais.

\section{Competências importantes para a tomada de decisão no ambiente IFRS}

Segundo Coda (2016), as empresas vêm readequando as suas estruturas e processos, visando maior agilidade em suas tomadas de decisões e, consequentemente, têm sido necessárias novas competências de seus colaboradores. As empresas valorizam as competências técnicas, uma vez que são diretamente associadas ao conteúdo do cargo; todavia, são as competências comportamentais que o indivíduo possui que determinam sua capacidade de se comunicar, trabalhar com equipes, liderar pessoas e se manter emocionalmente estável para assumir as responsabilidades e decisões inerentes ao ambiente organizacional, trazendo resultados positivos para a organização (CODA, 2016; LE DEIST; WINTERTON, 2005; MCLAGAN, 1989).

Tanto as competências técnicas quanto as comportamentais compõem as competências profissionais, definidas como a capacidade de um profissional de demonstrar se é capaz ou não de exercer determinada função; essas competências são divididas em competências gerais - que são as mais presenciadas em profissionais e nos mais diversos sistemas de gestão, e competências específicas - que são mais limitadas, sendo aquelas essenciais para o desempenho de determinados cargos e tarefas (CODA, 2016).

Com a alta complexidade dos processos de implantação do IFRS em uma instituição financeira, para que um profissional possa lidar com as normas internacionais são necessárias algumas competências primordiais. Para Coda (2016), a implantação do IFRS no Brasil trouxe uma complexidade muito grande, fazendo que profissionais se deparem com um cenário com poucas informações, demandando dos profissionais diferentes competências ao trabalharem com IFRS.

Em uma pesquisa com profissionais das áreas contábil e financeira que buscavam especialização em temas de IFRS, e utilizando entrevistas e o diagnóstico MARE de orientações, Coda (2016) identificou algumas competências essenciais para o profissional que atua no ambiente de IFRS e que são relacionadas ao processo de tomada de decisão exigido nesse ambiente. São elas: 
- Consultoria e aconselhamento (orientar outras áreas do negócio, buscando compreender atividades operacionais e fornecer conhecimento técnico).

- Análise de cenário e de negócios (desempenhar tarefas analíticas e fornecer diagnósticos do negócio levando em conta tanto o ambiente interno quanto o externo; estabelecer relações custo-benefício para a implantação do IFRS).

- Comunicação (escrever comunicados e relatórios sobre as vantagens e os impactos nos demonstrativos financeiros após a implantação do IFRS; fazer palestras e apresentações).

- Gestão (fazer a gestão do desempenho da equipe; ter capacidade de ampliar a visão do negócio; cuidado da integração entre a contabilidade e outras áreas do negócio; ter postura estratégica e influenciadora do desempenho de áreas-chave do negócio).

- Lida com questões normativas (garantir o cumprimento de normas e prazos).

- Ética (elaborar e publicar demonstrativos financeiros de modo transparente e ético).

Coda (2016) ressalta que as competências profissionais listadas envolvem tanto aspectos técnicos quanto comportamentais; embora tenham sido apontadas como importantes pelos profissionais que atuam no ambiente IFRS, utilizando o instrumento Mare, o referido autor (2016) apontou que elas não fazem parte do perfil dominante dos profissionais.

\section{PROCEDIMENTOS METODOLÓGICOS}

Esta pesquisa se enquadra como descritiva e segue uma abordagem qualitativa (RICHARDSON, 2007). Possui como unidade de análise o processo de tomada de decisão na estruturação do ambiente contábil para implantação do IFRS 9, na instituição financeira privada analisada.

Os sujeitos da pesquisa são funcionários da instituição financeira privada analisada, todos atuando em uma área relacionada a finanças, sendo essa área a responsável pela preparação do ambiente para implantação do IFRS 9 na instituição. Foram entrevistados funcionários dos níveis operacional, gerencial e executivo dessa área, garan- 
tindo-se a regra de representatividade da amostra para um procedimento qualitativo (BARDIN, 2016, p. 127). A instituição privada foi escolhida, tendo em vista que ela estava no processo de definição de processos para implantação dessa norma a partir de 2018.

A técnica de coleta de dados utilizada na referida pesquisa é a entrevista semiestruturada, seguindo-se um roteiro previamente estabelecido. O roteiro contém os seguintes tópicos:

- Em sua opinião, quais são os aspectos críticos na implantação do IFRS 9? Por exemplo, o que é mais crítico: a alteração na classificação dos instrumentos financeiros ou ainda, a mensuração nas estimativas para perdas?

- Quais são as principais decisões relacionadas a esses aspectos críticos? Por exemplo, na alteração de sistemas, de processos e na preparação de pessoas para a implantação do IFRS 9?

- Para você, essas decisões são mais racionais (inspiradas em critérios previamente definidos) ou mais fundamentadas em sua expertise (sua experiência profissional e pessoal)? Explique por que considera que a decisão é mais racional ou mais fundamentada em expertise.

- Se tivesse de classificar essas decisões, você diria que envolvem mais incerteza (chance de erro conhecida) ou mais ambiguidade (informações de chance de erro que são contraditórias)? Explique por que faz essa classificação das decisões adotadas no ambiente IFRS 9.

- Qual é sua percepção dos riscos relacionados às suas decisões no ambiente IFRS 9? Você diria que esses riscos são mais para a organização, para sua vida profissional ou para os que sofrem os efeitos da decisão? Explique.

- Analisando algumas das propostas seguintes, diga qual delas é mais frequente nas decisões adotadas no dia a dia:

a) Decido com base em eventos que ocorreram recentemente e que estão em minha memória. b) Decido com base em características que eu possa identificar como típicas 
de uma situação. c) Decido considerando que há inúmeros fatores que acabam fortalecendo as minhas suposições anteriores.

d) Decido utilizando julgamentos com alguma base afetiva (influência de sentimentos sobre minha decisão).

- Quais foram os processos seguidos para a formação de expertise em suas áreas de atuação? Como você desenvolveu sua competência técnica? Quais foram os momentos de sua carreira que você considera essenciais para a formação de sua expertise? Qual o grau de importância que atribui ao desenvolvimento de habilidades interpessoais para o desenvolvimento de sua expertise?

- Considerando o profissional que atua no ambiente de IFRS 9, quais seriam as competências para tomar decisões relacionadas ao IFRS 9?

- Como você faria para formar um bom decisor para o ambiente de IFRS 9?

- Tem algo a acrescentar sobre seu processo decisório? De modo geral, sobre a forma como toma decisões em ambientes econômicos/financeiros?

Todas as entrevistas foram gravadas e transcritas. Os dados foram analisados utilizando-se a técnica de análise de conteúdo partindo-se de categorias preestabelecidas (as questões do roteiro). As inferências foram feitas a partir da comparação entre as respostas às diferentes categorias analisadas. As unidades de registro são os temas que apareceram nas falas dos entrevistados (BARDIN, 2016, p. 135) em cada categoria. Não foram realizadas análises estatísticas (a partir da quantificação dos resultados) ou provas de validação, conforme proposto por Bardin (2016, p. 132).

\section{APRESENTAÇÃO E DISCUSSÃO DOS RESULTADOS}

A seguir, são apresentados - em categorias preestabelecidas - os resultados das entrevistas realizadas com os cinco funcionários da instituição financeira selecionada para o estudo que estavam participando do processo de implantação da norma IFRS 9. A Tabela 1 apresenta o perfil dos entrevistados e os dados relacionados às entrevistas. 
TABELA 1 - Resumo dos entrevistados e das entrevistas

\begin{tabular}{cccccccc}
\hline Sigla & Entrevistado & Cargo & $\begin{array}{c}\text { Tempo de } \\
\text { empresa }\end{array}$ & Idade & Sexo & $\begin{array}{c}\text { Data da } \\
\text { entrevista }\end{array}$ & $\begin{array}{c}\text { Tempo de } \\
\text { duração }\end{array}$ \\
\hline A & D.P. & Consultor & 11 meses & 39 anos & M & $15 / 09 / 2017$ & $17 \min 16$ \\
\hline B & J.N. & $\begin{array}{c}\text { Superintendente- } \\
\text { geral }\end{array}$ & 7 anos & 44 anos & M & $25 / 09 / 2017$ & $20 \min 19$ \\
\hline C & R.G. & $\begin{array}{c}\text { Superintendente- } \\
\text { geral }\end{array}$ & 6 anos & 42 anos & M & $02 / 10 / 2017$ & 20 min59 \\
\hline D & I.S. & Gerente & 6 anos & 28 anos & M & $06 / 10 / 2017$ & $50 \min 22$ \\
\hline E & A.K. & Analista & 8 anos & 29 anos & F & $27 / 10 / 2017$ & $21 \min 47$ \\
\hline
\end{tabular}

Fonte: Elaborada pelos autores.

\section{Aspectos críticos na implantação da norma IFRS 9}

Na Tabela 2, apresenta-se o resultado resumido das falas dos entrevistados em relação à categoria "Aspectos críticos para implantação da norma IFRS9".

TABELA 2 - Aspectos críticos na implantação da norma IFRS 9

\section{Entrevistado}

"[...] o mais crítico foi a classificação, não dos instrumentos, mas dos estágios [...] porque a norma não é objetiva nisso e acredito que no mercado cada banco pode fazer um

A pouco diferente. [...] E o segundo foi constituir o life time dos contratos, porque também não era costume do banco trabalhar com este horizonte [...] então foi um desafio assim meio diferente em relação ao que se pratica hoje no mercado".

“[...] a apuração e as provisões para perdas costumam ser mais críticas, principalmente

B fora do Brasil [...] A classificação e mensuração sim é uma grande questão aqui para nós, por conta de todo o mapeamento que tem de ser feito, de modelo de negócios, avaliação dos portfólios, avaliação dos contratos individualizados de ativos financeiros".

“[...] a parte de mensuração de perdas, [...] porque a partir de hoje são julgamentos subjetivos, então você não vai mais se prender a simplesmente fazer uma provisão por

C estatística, vai ter que ter muito mais a visão do negócio e conhecer muito mais o segmento dos clientes e identificar quais são os segmentos da economia que estão críticos naquele momento. Então vai ser muito mais dinâmico do que é hoje”. 
TABELA 2 - Aspectos críticos na implantação da norma IFRS 9

\section{Entrevistado}

"[...] vou lhe dizer que ambos são muito complexos [...] a forma de classificação, dependendo da intenção do produto, é muito mais ampla e requer muito mais intepretações das instituições [...] o mais difícil vai ser a questão da avaliação das classificações dos títulos, porque não envolve só a contabilidade, envolve todo um processo no qual a área de produtos vai ter que ser afetada. Então o cara na hora de desenhar um novo produto, ele terá que avaliar qual o impacto disso em termos de custos para o banco. Porque, dependendo da forma que você fizer, vai gerar um efeito no resultado ou no patrimônio líquido".

"A estimativa de perda é mais crítica [...] pois você está modificando a forma que mensura, então quando passa de perda incorrida para perda esperada, espera um

E aumento da provisão. Já na parte de classificação, por mais que agora você tenha que considerar o modelo de negócio e tudo mais, está noventa por cento alinhado com o conceito que havia antigamente, então você não espera muitas mudanças nesse sentido".

Fonte: Elaborada pelos autores.

Observa-se que, entre as respostas, três delas ressaltam a mensuração das estimativas para perdas como o aspecto mais crítico na implantação do IFRS 9. O entrevistado A cita que o maior desafio é especificamente a classificação dos estágios de estimativas de perdas, visto que a norma é subjetiva nessas definições. Outros dois entrevistados afirmam que o ponto mais crítico é a classificação dos instrumentos financeiros, pois a avaliação e a tratativa dada a esses instrumentos impactará o resultado e o patrimônio líquido da instituição.

Do ponto de vista de Mintz (2011), o IFRS integra uma abordagem inspirada muito mais em princípios contábeis do que em regras. De acordo com o sistema norteado por princípios, deve-se considerar a substância econômica dos dados financeiros e sua fidelidade de representação, para fazer julgamentos profissionais acerca da utilidade da informação financeira. Portanto, os aspectos mais críticos apontados na implantação da norma IFRS 9 envolvem os julgamentos profissionais para medir e atenuar os impactos no resultado contábil e no patrimônio líquido das instituições financeiras. 


\section{Principais decisões na implantação da norma IFRS 9}

\section{Na Tabela 3, apresenta-se o resultado resumido das entrevistas realizadas para a categoria preestabelecida de "Principais decisões na implantação da norma IFRS 9".}

TABELA 3 - Principais decisões na implantação da norma IFRS 9

\section{Entrevistado}

"Acho que a maior dificuldade é o aspecto cultural [...] o desafio que temos é, com estas definições que foram tomadas, passar para o resto do banco, para a equipe de capital que

A está de nosso lado, para todo mundo conhecer estas definições novas que acredito que, pela tendência, daqui a dois anos o mercado todo já ter migrado, já estar reportando tudo em IFRS 9".

\begin{tabular}{l}
\hline “[...] a parte sistêmica de fato vai ser uma questão que terá de ser resolvida e equalizada \\
B $[\ldots]$ Temos algumas decisões importantes a tomar, a questão de designar um portfólio a \\
fair value option ou não; já migrar nossos hedges contábeis para a regra do IFRS ou \\
manter da forma que está, como é outra opção”.
\end{tabular}

“[...] em termos de, por exemplo, como se administram os custos incorridos nos processos de recuperação de clientes que já estão inadimplentes. Então, como no banco C tudo é descentralizado [...] você não consegue atribuir esses custos direto na operação. [...] o grande desafio da área de riscos vai ser fazer o parâmetro para colocar essa conta dentro do processo".

“[...] nossa publicação em IFRS hoje não é um sistema preparado para calcular o IFRS, ele é uma adaptação no fim [...]. Mas agora com o IFRS 9, não necessariamente conseguimos

$\mathrm{D}$ fazer essas adaptações no fim. [...] então esse já é um indício de mudanças sistêmicas. [...] E aqui, na contabilidade, imaginamos que, com base na interpretação do Banco Central, o quanto mais flexível ele for com isso, vamos fazer uma alteração no fim; o quanto mais rígido ele for na questão da interpretação do IFRS 9, vamos ter de alterar os sistemas”.

"Na parte de PDD [...] a intenção é que você chegue muito próximo do valor BRGAAP e a norma não especifica como fazer [...] porque as regras não são exatamente iguais a 2.682, [...] o IFRS não estabelece um percentual mínimo conforme os dias de atraso, ele deixa aberto. Então nós temos que tentar alinhar a metodologia do IFRS para conseguir ter poucas distorções com relação ao BRGAAP. [...] Um dos pontos é quando fazemos vários 'arrastos' para operações e fazemos cem por cento de PDD, mesmo antes de chegar aos 180 dias de atraso [...]. Mas, para fins de IFRS, é difícil chegar aos cem por cento de PDD [...]. Então eu preciso tentar chegar em um valor próximo [...] só que nós temos o medo de ficar muito distante do BRGAAP".

Fonte: Elaborada pelos autores. 
Pode-se verificar a menção de diversas decisões importantes na implantação do IFRS 9. Entre elas, três entrevistados citaram as decisões relacionadas à implantação de alterações sistêmicas, que vão incorrer em custos para o banco, e devem ser avaliadas com prudência. Outra decisão importante é a metodologia, que deverá ser elaborada para atribuir individualmente os custos incorridos em uma operação - necessário para o cálculo da taxa efetiva de juros -, pois atualmente não há um parâmetro que permite alocar esses custos diretamente às operações.

Conforme Dulitz (2009), a implantação do IFRS é um processo de alta complexidade, mas é também uma perfeita oportunidade para que as empresas revejam suas políticas contábeis, seus processos de negócios, contratos e estrutura de transações. Schmutte e Duncan (2009) concluem que o julgamento profissional sempre foi um elemento crítico na contabilidade. A tendência das mudanças em pronunciamentos contábeis é que sejam fornecidas menos orientações específicas para uma maior utilização de julgamentos contábeis. Nesse contexto, os profissionais da contabilidade têm um papel fundamental no desenvolvimento do processo decisório. Pode-se perceber que, na fala dos entrevistados, há uma situação de incerteza com a implantação do IFRS 9, que pode ser notada pelo risco apontado e pelo "medo de ficar muito distante do BRGAAP".

\section{Razão e expertise nas decisões na implantação da norma IFRS 9}

Na Tabela 4, apresenta-se o resultado resumido das entrevistas realizadas para a categoria preestabelecida de "Razão e expertise na tomada de decisão na implantação da norma IFRS 9".

TABELA 4 - Razão e expertise nas decisões na implantação da norma IFRS 9

Entrevistado

A
“[...] minha expertise, ela ajudou na parte de metodologia. [...] você precisa de uma metodologia para poder tomar as decisões, poder fazer estudos e a partir destes estudos tomar as decisões [...] 90\% foram inspirados em estudo”. 
TABELA 4 - Razão e expertise nas decisões na implantação da norma IFRS 9

\begin{tabular}{cl}
\hline Entrevistado & \\
\hline \multirow{2}{*}{ B } & $\begin{array}{l}\text { "[...] tem os dois aspectos, a expertise é importante para você saber qual o efeito que uma } \\
\text { decisão dessa natureza vai gerar no futuro, e não pode ser uma decisão fundamentada } \\
\text { somente no efeito imediato que ela traz. [...] ambos os aspectos são importantes". }\end{array}$ \\
\hline \multirow{3}{*}{ "[...] acho que são as duas coisas nas suas devidas proporções. [...] identificar } \\
previamente possíveis cenários desfavoráveis, para você ir 'piorando' as provisões de \\
forma adequada. E penso que agora a questão toda se refere ao cenário econômico, \\
de como ele se comporta com relação ao que se projeta".
\end{tabular}

Fonte: Elaborada pelos autores.

Percebe-se que todos os entrevistados afirmam que tomam suas decisões com base na sua expertise e em critérios previamente definidos e que estes fatores são interdependentes. Apesar de os entrevistados afirmarem que utilizam em proporção maior a tomada de decisão racional em suas decisões (sistema 2), pode-se verificar na análise das entrevistas como um todo que são mais inspirados na expertise (sistema 1) "porque a norma não necessariamente vai entrar no detalhe, em algumas situações ela será superficial”.

Conforme já discutido, as decisões com base no sistema 1 são rápidas, automáticas, sem esforço explícito mas envolvendo conteúdos emocionais; as decisões com base no sistema 2 referem-se ao raciocínio mais lento, consciente, esforçado, com esforço explícito e lógico. $\mathrm{O}$ uso da expertise é o uso da decisão rápida. O risco do uso da expertise (experiências aprendidas) é de que as pessoas não considerem mudanças nas situações já estabelecidas, assumindo que o presente se comporta igual ao passado, caindo assim nos vieses decorrentes das heurísticas de disponibilidade e representatividade. 


\section{Incerteza e ambiguidade nas decisões da implantação da norma IFRS 9}

Na Tabela 5, apresenta-se o resultado resumido das entrevistas realizadas para a categoria preestabelecida de "Incerteza e ambiguidade nas decisões da implantação da norma IFRS 9".

TABELA 5 - Incerteza e ambiguidade nas decisões da implantação da norma IFRS 9

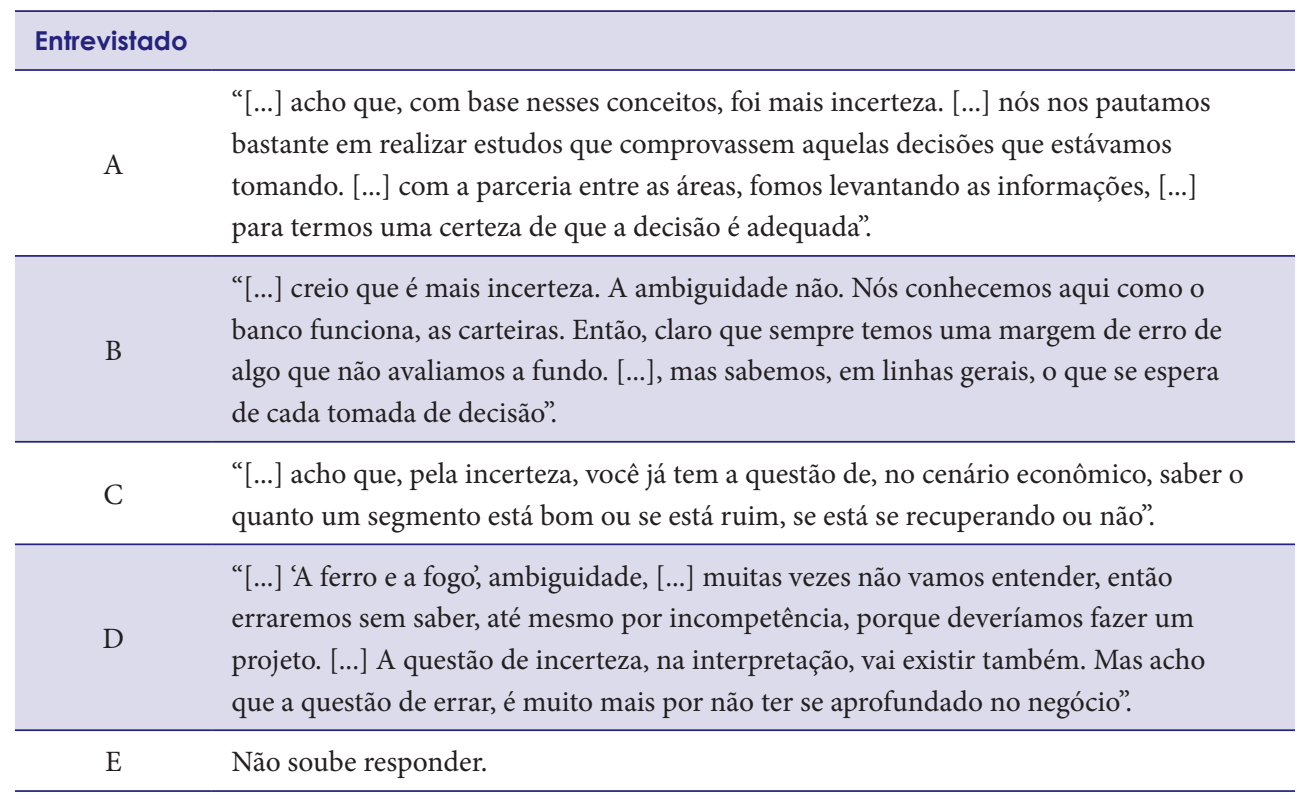

Fonte: Elaborada pelos autores.

Pode-se verificar que a maioria dos entrevistados declararam que suas decisões com relação à implantação da norma IFRS 9 são mais fundamentadas em incertezas e apenas um dos participantes respondeu que envolve mais a ambiguidade, embora não tenha definido claramente o que é essa ambiguidade na situação de implantação do IFRS.

A incerteza está diretamente associada ao risco e em decisões dessa natureza os sujeitos não têm todas as informações necessárias para decidir. Assim, podem estar sujeitos aos vieses decorrentes da heurística de representatividade, tipificando os problemas relacionados às situações atuais pela incapacidade de defini-los claramente. 


\section{Riscos das decisões da implantação da norma IFRS 9}

Na Tabela 6, apresenta-se o resultado resumido das entrevistas realizadas para a categoria preestabelecida de "Percepção dos riscos das decisões da implantação da norma IFRS 9".

TABELA 6 - Percepção dos riscos das decisões da implantação da norma IFRS 9

\begin{tabular}{|c|c|}
\hline Entrevistado & \\
\hline A & $\begin{array}{l}\text { "Acho que há alguns riscos, como até costumo comentar aqui na área, esta é uma } \\
\text { primeira versão do modelo IFRS [...] estamos fazendo estudos do impacto } \\
\text { macroeconômico na carteira, então acreditamos que existem alguns riscos de } \\
\text { eventualmente algumas decisões não serem ótimas para este momento [...] e a } \\
\text { organização toda tem de estar envolvida, não adianta só eu ter este risco". }\end{array}$ \\
\hline B & $\begin{array}{l}\text { “[...] enquanto o IFRS } 9 \text { estiver restrito a um balanço que não é aquele balanço oficial da } \\
\text { escrituração contábil, temos algum risco que é regulatório [...] Como o Banco Central já } \\
\text { vem trabalhando em uma proposta de como seria o IFRS } 9 \text { na escrituração contábil das } \\
\text { instituições financeiras, aí de fato o risco se torna maior, por conta dela afetar } \\
\text { financeiramente o número oficial que o banco vai divulgar, que vai ter todos os efeitos } \\
\text { decorrentes". }\end{array}$ \\
\hline $\mathrm{C}$ & $\begin{array}{l}\text { "Os riscos em relação a tudo o que você montar de critério, em um primeiro momento, } \\
\text { você está superestimando ou subestimando, a grande questão ao longo do tempo vai ser } \\
\text { calibrar esse meio-termo". }\end{array}$ \\
\hline $\mathrm{D}$ & $\begin{array}{l}\text { "Existe risco para todo o lado [...] na crise que teve, por exemplo, nos Estados Unidos, } \\
\text { os bancos estão em perdas incorridas, do dia para a noite, ele tem de calcular eventual } \\
\text { perda esperada, então o banco vai dar prejuízo, então tem impacto na vida econômica } \\
\text { [...] O profissional que, por exemplo, na área de análise, avaliou de uma forma indevida } \\
\text { um instrumento que deu uma oscilação no resultado, eventualmente essa pessoa pode } \\
\text { ser interpretada de várias formas então vai prejudicar com certeza também a questão do } \\
\text { profissional [...] Então, a questão do risco sistêmico, principalmente com relação a } \\
\text { marcação a mercado, é o resultado do banco, ele vai querendo ou não ser muito mais } \\
\text { volátil. [...] você avalia como life time, ou seja, cem por cento da operação para resultado, } \\
\text { mas no minuto seguinte essa carteira melhora, você reverte todo resultado. [...] E isso } \\
\text { tudo está oscilando o resultado contábil sem caixa algum [...]. Então com certeza, o } \\
\text { profissional vai ser impactado, o mercado vai ser impactado e muito por conta dessa } \\
\text { oscilação de resultado". }\end{array}$ \\
\hline
\end{tabular}


TABELA 6 - Percepção dos riscos das decisões da implantação da norma IFRS 9

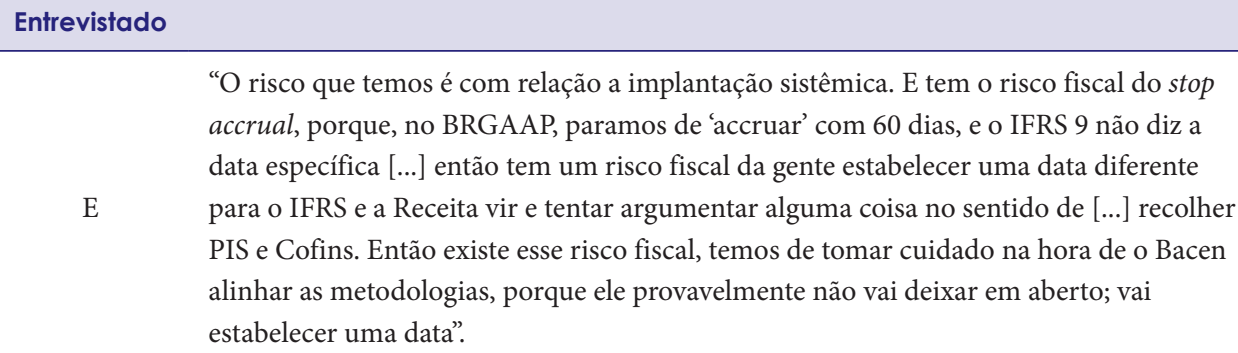
accrual, porque, no BRGAAP, paramos de 'accruar' com 60 dias, e o IFRS 9 não diz a data específica [...] então tem um risco fiscal da gente estabelecer uma data diferente $\mathrm{E}$ para o IFRS e a Receita vir e tentar argumentar alguma coisa no sentido de [...] recolher PIS e Cofins. Então existe esse risco fiscal, temos de tomar cuidado na hora de o Bacen alinhar as metodologias, porque ele provavelmente não vai deixar em aberto; vai estabelecer uma data".

Fonte: Elaborada pelos autores.

Analisando-se a tabela, podem-se apontar diversos riscos na implantação da norma IFRS 9 na visão dos entrevistados. Destacam-se os riscos sistêmicos, pois, conforme citado pelo entrevistado A, "esta é uma primeira versão do IFRS 9", e é provável que em um primeiro momento os cálculos estejam superestimados ou subestimados, devendo ser calibrados no período de pós-implantação. De acordo com o entrevistado B, haverá efetivamente o risco regulatório no momento em que o BACEN incorporar a norma IFRS 9 ao balanço oficial da escrituração contábil, suscitando todos os riscos decorrentes.

Há o risco fiscal, citado pelo entrevistado E, pela possibilidade de mudança no recolhimento de impostos. Também há riscos para os profissionais que passarão a fazer julgamentos de classificação de instrumentos que impactam o resultado do banco. Ademais, os estágios de classificação de estimativas para perdas farão que o resultado contábil das instituições financeiras oscile constantemente, elevando o risco de mercado.

Dada a obrigatoriedade da implantação da norma, as empresas que seguem os padrões internacionais de contabilidade terão que realizar o processo de implementação dos novos conceitos apresentados. De acordo com Ramos (2014), são procedimentos complexos que requerem tomadas de decisões críticas, podendo influenciar significativamente os resultados da empresa.

A norma IFRS 9 também exige julgamentos constantes no ambiente pós-implantação, no qual os profissionais devem se fundamentar nos princípios da norma para escolher a melhor alternativa superestimativa (ou subestimativa dos dados) expressa a possi- 
bilidade de ocorrência dos vieses relacionados à heurística de representatividade, especialmente a insensibilidade aos índices básicos, ao tamanho da amostra, e à heurística de teste de hipóteses (confirmação).

\section{Estilo de decisão e utilização de heurísticas}

Na Tabela 7, apresenta-se o resultado resumido das entrevistas realizadas para a categoria preestabelecida de "Estilo de decisão e utilização de heurísticas".

TABELA 7 - Estilo de decisão e utilização de heurísticas

\begin{tabular}{|c|c|}
\hline Entrevistado & \\
\hline A & $\begin{array}{l}\text { “[...] decido com base em características que eu possa identificar como típicas de uma } \\
\text { situação. [...] quando eu posso identificar não é só eu pessoa humana [...] existe uma } \\
\text { metodologia, existe um teste, existe uma forma que eu consigo corroborar } \\
\text { estatisticamente que aquela decisão é adequada ou não, e com base também no histórico } \\
\text { passado". }\end{array}$ \\
\hline B & $\begin{array}{l}\text { “[...] decido considerando que existem inúmeros fatores que acabam fortalecendo as } \\
\text { minhas suposições anteriores. [...]. E em alguma medida [...] decido com base em } \\
\text { características que eu possa identificar como típicas de uma situação". }\end{array}$ \\
\hline $\mathrm{C}$ & $\begin{array}{l}\text { "[...] decido considerando que existem inúmeros fatores que acabam fortalecendo as } \\
\text { minhas suposições anteriores. [...] trabalhamos aqui, fundamentados em fatos, bases } \\
\text { analíticas, estudos, fatos concretos, para identificar distorções e erros". }\end{array}$ \\
\hline $\mathrm{D}$ & $\begin{array}{l}\text { “[...] decido considerando que existem inúmeros fatores que acabam fortalecendo as } \\
\text { minhas suposições anteriores. [...] então muitas vezes escolhemos de acordo com nossa } \\
\text { opinião e tentamos comprovar para encurtar o caminho. Mas isso também parte de você } \\
\text { ter uma experiência do passado. Você com certeza vai mais direcionado porque já } \\
\text { passou por uma experiência. [...] também [...] decido com base em eventos que } \\
\text { ocorreram recentemente e que estão em minha memória; [...] e decido com base em } \\
\text { características que possa identificar como típicas de uma situação”. }\end{array}$ \\
\hline $\mathrm{E}$ & $\begin{array}{l}\text { “[...] base afetiva é zero. Acho que decido com base em características típicas de uma } \\
\text { situação. E essa questão dos fatores que fortalecem as suposições anteriores também. } \\
\text { Temos essas premissas e decidimos à medida que vamos vendo como se comporta a } \\
\text { carteira banco e afins”. }\end{array}$ \\
\hline
\end{tabular}

Fonte: Elaborada pelos autores. 
Pode-se verificar que, entre os entrevistados, quatro deles revelaram que decidem com base em características que eles possam identificar como típicas de uma situação. Três expressaram que decidem considerando que há inúmeros fatores que acabam fortalecendo as suas suposições anteriores e um respondeu que decide com base em eventos que ocorreram recentemente e que estão em sua memória. Todos os participantes afirmaram que não utilizam julgamentos com base afetiva nas tomadas de decisões.

Analisando-se as entrevistas, é possível notar que a heurística mais utilizada foi a da representatividade - os indivíduos tendem a procurar peculiaridades que correspondam a estereótipos formados anteriormente. A heurística do teste de hipótese positiva foi a segunda mais mencionada. Além disso, foi citada a heurística da disponibilidade - processo de julgamento conforme a facilidade com que as ocorrências vêm à mente.

Apesar de todos os participantes afirmarem que jamais utilizam a heurística do afeto, foi possível verificar nas entrevistas menções a sentimentos como medo e inspiração, evidenciando a presença desta heurística. O uso de heurísticas é coerente com a afirmação de uso de expertise nas decisões; mostra também que a decisão racional é restrita, como já afirmava Simon, com sua Teoria da Racionalidade Limitada (1955).

\section{Processos de formação da expertise e habilidades interpessoais}

Na Tabela 8, apresenta-se o resultado resumido das entrevistas realizadas para a categoria preestabelecida de "Processos de formação da expertise e habilidades interpessoais".

TABela 8 - Processos de formação da expertise e habilidades interpessoais

\begin{tabular}{ll}
\hline Entrevistado & \\
\hline & "O que me ajudou mais foi minha experiência específica em modelagem. [...] e aí duas \\
& coisas que considero fundamentais, primeiro a minha exposição já ao que eram os \\
& requisitos de Basileia [...] ou as regras atuais aqui no mercado brasileiro [...]considero \\
A & que o momento da minha carreira que também me ajudou bastante foi não só ter me \\
& especializado em Basileia, mas eu trabalhei com várias outras modelagens né, então, \\
& risco, fraude, renda, faturamento, então isso acho que trouxe um pouco mais de skill \\
& técnico".
\end{tabular}


TABELA 8 - Processos de formação da expertise e habilidades interpessoais

\section{Entrevistado}

“[...] eu não sou contador, então parti para uma expertise de uma formação um tanto diferente, mas de certa forma correlata, eu sou economista. [...] um passo importante para adquirir expertise foi a pós-graduação em controladoria e finanças que ajudou bastante, mas foi muito estudo e muito trabalho na área que acabou resultando nesta formação que eu tenho hoje [...] a minha expertise vem da experiência mesmo de trabalho em si. [...] a habilidade interpessoal também é importante, na medida em que não sabemos tudo, né, ninguém é autossuficiente".

"[...] eu segui um padrão de gestores que acreditavam na experiência em relação a forma de você identificar algum tipo de erro, que é olhando para o 'macro' [...] o que eu tento passar para as próximas pessoas que estão diretamente comigo, toda essa experiência com relação de como identificar as coisas e como resolver os problemas de forma C concreta [...] ser curioso, questionar sempre a parte técnica, na questão de conceitos que você não domina, colocar seu ponto de vista, aquilo que você acha que seria um conceito [...] o que levo de experiência, e passo para quem está comigo, é justamente ter essa curiosidade de entender o que está fazendo efetivamente [...] o conhecimento sempre agrega e nunca é perdido, é isso que penso e que eu levo aqui para o trabalho e vida profissional".

"[...] com relação à técnica, eu tento de alguma forma avaliar o cenário em que eu estou inserido, de alguma forma fazer mais do que os demais [...] destaco muito a curiosidade e de certa forma nos prepararmos, para quando tivermos oportunidade [...] não acredito

$\mathrm{D}$ que foi a minha vida acadêmica que me ajudou a destoar, foi a minha vida profissional, acho que mais a prática do que eventualmente a técnica, mais fazendo, entendendo [...] quanto mais rápido conseguir desempenhar um papel técnico, mais você terá tempo para analisar, para desenvolver [...] acho que, mais importante do que saber falar, é saber ouvir".

"Com relação à classificação de modelos do IFRS, ter participado do ICAP, que é um relatório de gerenciamento de riscos, eu tive contato com o pessoal de risco de mercado, e tive uma noção de como funciona o risco, a tesouraria, e isso me ajudou um pouco".

Fonte: Elaborada pelos autores.

As respostas a essa categoria mostram que a formação técnica em IFRS não é considerado um fator determinante para que os profissionais trabalhem com IFRS 9; são importantes suas experiências passadas que lhes capacitaram desenvolver algumas características essenciais para se trabalhar nessa área, como dedicação ao trabalho (atitude) e 
estudo de assuntos relacionados (conhecimento). Também se pode destacar a curiosidade dos entrevistados como um fator essencial para terem o conhecimento que possuem.

As respostas alinham-se à afirmação de que as competências de um profissional derivam das competências organizacionais, sendo por meio dessas competências que são analisadas a capacidade de cada pessoa (CODA, 2016); além disso, as competências específicas para o IFRS talvez não tenham sido alvo dos cursos de formação acadêmica desses profissionais, tendo em vista as suas idades, a provável época de conclusão de sua graduação e a implantação do IFRS.

\section{Competências desejáveis aos profissionais do ambiente da norma IFRS 9}

Na Tabela 9, está o resultado resumido das entrevistas realizadas para a categoria preestabelecida de "Competências desejáveis aos profissionais do ambiente da norma IFRS 9".

TABELA 9 - Competências desejáveis aos profissionais do ambiente da norma IFRS 9

\begin{tabular}{|c|c|}
\hline \multicolumn{2}{|c|}{ Entrevistado } \\
\hline A & $\begin{array}{l}\text { "[...] acho que a competência que é importante é todo mundo ter na cabeça essa noção de } \\
\text { risco de crédito [...] considero bem importante as pessoas terem conhecimento de que } \\
\text { existe o risco de crédito e como identificar quando ele está se deteriorando, como } \\
\text { identificar e como atuar, acho que o banco já faz isso bem hoje". }\end{array}$ \\
\hline B & $\begin{array}{l}\text { “[...] primeiro uma característica analítica muito grande, isso a área de normas tem } \\
\text { bastante. A capacidade de ler dez vezes um texto até entender o que está falando e saber } \\
\text { com clareza. [...] relacionamento interpessoal, seja com as áreas de produtos, áreas de } \\
\text { negócios, e com os próprios gestores contábeis é muito importante [...] são essas duas } \\
\text { coisas: a capacidade analítica grande e uma boa capacidade de relação interpessoal com } \\
\text { quem conhece os números mais a fundo. }\end{array}$ \\
\hline $\mathrm{C}$ & $\begin{array}{l}\text { “[...] o que é importante é conhecer o segmento dos seus clientes, conhecer a dinâmica } \\
\text { da economia e como ela se comporta, quais são as tendências, as projeções, e estar } \\
\text { informado com relação a essas mudanças [...] o grande mérito de quem está dentro } \\
\text { desse processo é perceber as situações que estão acontecendo de fato e adequar o que } \\
\text { chamamos de perda esperada no tempo correto". }\end{array}$ \\
\hline
\end{tabular}


TABELA 9 - Competências desejáveis aos profissionais do ambiente da norma IFRS 9

\begin{tabular}{cl}
\hline Entrevistado & \\
\hline & "[...] ele tem de entender muito do negócio como um todo, nem tanto de contabilidade, \\
& ele tem de entender a essência econômica do negócio $[\ldots]$ a contabilidade tem os \\
& princípios, então. assim, pode ter o IFRS $1,2,3,9,500 \ldots$, o que importa é sempre \\
& o princípio [...] você precisa ter uma visão lógica de não fugir muito dos princípios, e \\
D & aí interpretar item a item da norma [...] tem de ter realmente essa visão muito clara de \\
& quais são os princípios, isto é fundamental, e, quanto mais dos negócios ela entender, \\
& ela vai conseguir usar como referência". \\
\hline & "Ele tem de entender do negócio [...] não pode ficar só na teoria, tem de conversar com \\
& as áreas [...] entender os contratos, entender como a área de pricing põe os preços nos \\
& contratos, por exemplo [...] isso é o mais importante, saber do negócio". \\
\hline
\end{tabular}

Fonte: Elaborada pelos autores.

Uma das principais competências observadas nas respostas é que o profissional tenha um entendimento muito grande do negócio, pois, a partir desse conhecimento, o profissional terá uma competência analítica para a identificação dos seus riscos. Além disso, o profissional deve ter uma relação interpessoal muito boa para saber lidar não apenas com as pessoas, mas também com os produtos e as linhas de negócio em que irá atuar.

Essas respostas se alinham aos resultados da pesquisa conduzida por Coda (2016) especialmente no tocante à necessidade de saber fazer análise de cenário de negócio, desempenhar tarefas analíticas e fornecer diagnósticos do negócio, levando em conta tanto o ambiente interno como externo.

Deve-se destacar que alguns dos entrevistados destacaram algumas competências comportamentais, como relacionamento interpessoal, capacidade de liderar grupos ou trabalhar em equipes. Esse resultado é interessante, pois, para implantar novas sistemáticas, é preciso mudar rotinas; nesse cenário, as competências comportamentais são importantes para engajar pessoas, garantir comprometimento e manter a motivação.

\section{Formação de decisores no ambiente da norma IFRS 9}

A Tabela 10 traz o resultado resumido das entrevistas realizadas para a categoria preestabelecida de "Formação de decisores no ambiente da norma IFRS 9". 
TABELA 10 - Formação de decisores no ambiente da norma IFRS 9

\begin{tabular}{|c|c|}
\hline \multicolumn{2}{|c|}{ Entrevistado } \\
\hline A & $\begin{array}{l}\text { "Acho que conhecimentos abrangentes em risco de crédito é importante, e vontade de } \\
\text { aprender, porque é muita coisa nova [...] é importante que esta pessoa esteja aberta a } \\
\text { aprender coisas novas". }\end{array}$ \\
\hline B & $\begin{array}{l}\text { "[...] um bom decisor }[\ldots] \text { a pessoa precisa ter algo inato de tomar decisões e assumir } \\
\text { riscos }[\ldots] \text { tem de ser uma pessoa que tenha essa característica de ser alguém arrojado, } \\
\text { mas também ter a característica de saber ponderar todos os aspectos de cada tomada } \\
\text { de decisão". }\end{array}$ \\
\hline $\mathrm{C}$ & $\begin{array}{l}\text { "[...] a pessoa precisa buscar aquilo que não conhece, com a experiência de pessoas que } \\
\text { de alguma forma já vivenciaram todo um processo e possuem toda experiência no } \\
\text { sentido de ter visto muita coisa, e tentar transmitir isso de forma positiva". }\end{array}$ \\
\hline $\mathrm{D}$ & $\begin{array}{l}\text { "[...] eu teria de incentivar de alguma forma muita leitura, leitura neste sentido é } \\
\text { fundamental para você associar com os produtos e o que nós temos para aplicar [...] } \\
\text { ajudaria nesta questão de incentivar a leitura e interpretação, sempre olhando para a } \\
\text { linha mestre em principio contábil". }\end{array}$ \\
\hline $\mathrm{E}$ & $\begin{array}{l}\text { "[...] a pessoa tem de estar focada em ler muito e entender e, ao mesmo tempo, ter } \\
\text { liberdade para ter contato com as áreas, conhecer as pessoas que são essenciais e tentar } \\
\text { aprender o máximo possível [...] a pessoa precisa entender a teoria, mas também precisa } \\
\text { fazer o link com a prática”. }\end{array}$ \\
\hline
\end{tabular}

Fonte: Elaborada pelos autores.

Observa-se que, na Tabela 10, um dos principais aspectos relacionados aos entrevistados é que o profissional seja receptivo para novos desafios e para compreensão ampla dos princípios contábeis que são úteis na implantação e no entendimento do IFRS 9, além de muita prática e conhecimento nos produtos utilizados na empresa. Essa resposta é coerente com os dados obtidos por Coda em sua pesquisa (2016), na qual destaca como um dos desafios para o profissional contábil a compreensão da integração entre as áreas de negócio.

\section{Processo decisório em ambientes econômicos/financeiros}

Na Tabela 11, apresenta-se o resultado resumido das entrevistas realizadas para a categoria preestabelecida de "Processo decisório em ambientes econômicos/financeiros". 
TABELA 11 - Processo decisório em ambientes econômicos/financeiros

\begin{tabular}{cl}
\hline Entrevistado & \\
\hline A & Nada a acrescentar. \\
\hline "[...] meu processo decisório é sempre fundamentado primeiro na parte técnica, \\
segundo na análise do risco e severidade, se aquilo vai de fato trazer um risco para \\
a instituição ou não, e terceiro fundamentado também no quanto podemos ouvir \\
opiniões diversas em relação aquele ponto que não é tão claro. Eventualmente \\
quando o risco e a severidade são muito grandes em uma tomada de decisão, é \\
necessário que outras instâncias superiores saibam desses riscos e possam tomar \\
decisões com base nessa análise efetuada [...]".
\end{tabular}

Fonte: Elaborada pelos autores.

Nessa categoria, são apresentadas, de forma aberta, as considerações finais dos entrevistados a respeito do processo de tomada de decisão em geral, que complementam as respostas das categorias anteriores. As respostas inferem que aparecem temas como intuição, ouvir outras opiniões, equilibrar razão e emoção, todos aspectos comportamentais ou cognitivos relacionados à expertise. 
A intuição em realce pode ser manifestação de aprendizagens prévias, memorizadas, mas das quais não necessariamente se tem consciência, processo esse denominado memória implícita (STERNBERG, 2008). O equilíbrio entre razão e emoção é o proposto por Kahneman (2012) quando se refere aos sistemas 1 e 2 e à sua interação.

\section{CONSIDERAÇÕES FINAIS}

Este artigo buscou atender especificamente aos objetivos de identificar, em uma instituição financeira privada, quais são as decisões críticas referentes à estruturação do ambiente contábil para a implantação do IFRS 9 e identificar quais são as competências requeridas dos profissionais envolvidos com o processo de implantação do IFRS 9, por meio de entrevistas realizadas com os profissionais de uma instituição específica.

Os resultados permitem constatar que a alteração na mensuração das estimativas de perdas para o modelo de perdas esperadas é considerada o aspecto mais crítico da implantação da norma IFRS 9, sobretudo por conta da oscilação gerada no resultado das instituições financeiras, capaz de provocar interpretações equivocadas com relação ao aumento ou à queda do lucro contábil sem geração de caixa. A mudança de critérios na classificação dos instrumentos financeiros também é considerada um aspecto crítico, dada a subjetividade da norma em relação à avaliação dos modelos de negócio, que podem gerar impactos no resultado ou no patrimônio líquido das entidades, dependendo da categoria em que são classificados os instrumentos.

Os resultados também atestam que as principais decisões no processo de implantação da norma IFRS 9 estão relacionadas às alterações sistêmicas, mudanças dos estágios de estimativas de perdas, à alteração da classificação dos instrumentos financeiros em estoque, ao desenvolvimento de metodologias para classificação de novos instrumentos financeiros e à definição da metodologia de cálculo da taxa efetiva de juros das operações. No tocante aos riscos associados à implantação, foram destacados os riscos profissionais decorrentes de julgamentos inadequados, além dos riscos fiscais e regulatórios caso o BACEN decida adotar a norma IFRS 9 na escrituração contábil oficial das instituições financeiras. 
Em relação ao estilo de decisão dos profissionais envolvidos na estruturação do ambiente contábil para implantação da norma IFRS 9, constatou-se que os respondentes se consideram preponderantemente racionais em suas decisões, e que supõem que o modelo ideal em uma tomada de decisão seria uma junção entre racionalidade e expertise.

Contudo, no decorrer das entrevistas, foi possível identificar a utilização de heurísticas no processo de tomada de decisão, desviando estes indivíduos da racionalidade do sistema 2 (KAHNEMAN, 2012). Ademais, verificou-se a presença da influência de sentimentos nas decisões tomadas pelos entrevistados, quando estes citam o medo das consequências de uma decisão, bem como a inspiração em outros profissionais.

Quanto à análise das competências desejáveis aos profissionais que atuam no ambiente de implantação da norma IFRS 9, destacam-se a capacidade de bons relacionamentos interpessoais, a curiosidade na busca de novos conhecimentos, a capacidade analítica e - principalmente - um entendimento amplo do negócio. Ademais, constatou-se que a formação acadêmica não é considerada um fator determinante, mas sim a experiência profissional, capacitação e dedicação. Na formação de um bom decisor nesse ambiente, espera-se que o profissional já possua certa experiência prática e que esteja disposto a muito estudo, além de enfrentar os desafios proporcionados pela convergência dos procedimentos contábeis para a normatização internacional.

Enfatiza-se que, por sua natureza qualitativa e por ser restrito a uma instituição financeira específica, os resultados do referido estudo não podem ser generalizados para a população. Todavia, os achados podem colaborar para otimização dos processos de implantação de normas internacionais, pois trazem informações relevantes para profissionais que atuam em áreas que estejam sujeitas ou sejam relacionadas ao cumprimento dos padrões internacionais de contabilidade.

Recomenda-se que o estudo seja estendido a outras instituições e que os resultados sejam discutidos em ambientes acadêmicos para que sejam debatidas as ações necessárias ao desenvolvimento das competências que vêm sendo exigidas, especialmente no tocante ao julgamento e à crítica envolvidos nos processos decisórios. 


\section{THE DECISION PROCESS RELATED TO THE IMPLEMENTATION OF IFRS 9 IN A FINANCIAL INSTITUTION}

\section{ABSTRACT}

This article aims to identify, in a private financial institution, what are the critical decisions regarding the structuring of the accounting environment for the implementation of IFRS 9 and what are the competencies required of the professionals involved in this process. The work was developed from the application of interviews with employees participating in the decision-making process in the implementation of IFRS 9. For the data treatment, the content analysis was applied, and it was verified that the critical decisions in the implantation of the standard are related to changes in the stages of loss estimates, changes in the classification of financial instruments in inventory and development of methodologies for classification of new financial instruments. It was verified that among the skills required of the professionals involved in this process are the ability to have good interpersonal relationships, curiosity in the search for new knowledge, analytical capacity and a broad understanding of the business. This work has practical implications for organizations adopting international accounting standards, making it possible to understand the main decisions involved in the IFRS 9 implementation process, as well as the competencies identified as essential by these professionals. In addition, this study seeks to look at the IFRS 9 standard from an original perspective, considering the importance of accounting judgments, which derive from the decision profile of professionals working in this area.

\section{KEYWORDS}

IFRS 9. Decision making. Judgment.

\section{REFERÊNCIAS}

BADDELEY, A., ANDERSON, M.C.; EYSENCK, M. Memória. Porto Alegre: Artmed, 2011. BARDIN, L. Análise de conteúdo. Lisboa: Edições 70, 2016.

BAZERMAN, M. H. (2014). Processo decisório. Rio de Janeiro: Elsevier, 2014.

CAMERER, C.; LOEWENSTEIN, G.; PRELEC, D. Neuroeconomics: how neuroscience can inform economics. Journal of Economic Literature, Nashville, v. 43, n. 1, p. 9-64, 2005.

CODA, R. Competências comportamentais: como mapear e desenvolver competências pessoais no trabalho. São Paulo: Atlas, 2016. 
DULITZ, L. IFRS: A Preparer's point of view. Journal of Accountancy, New York, v. 207, n. 4, p. 46, 2009. Available in: http://eifrs.ifrs.org/eifrs/bnstandards/en/2017/ifrs09.pdf. Acesso em: 10 mai. 2017.

KAHNEMAN, D. A perspective on judgment and choice: mapping bounded rationality. American Psychologist, Washington, v. 58, n. 9, p. 697, 2003.

KAHNEMAN, D. Rápido e devagar: duas formas de pensar. São Paulo: Objetiva, 2012.

KAHNEMAN, D.; KLEIN, G. Conditions for intuitive expertise: a failure to disagree. American Psychologist, Washington, v. 64, n. 6, p. 515, 2009.

LE DEIST, F. D.; WINTERTON, J. What is competence? Human Resource Development International, London, v. 8, n. 1, p. 27-46, 2005.

MAIA, K. I. C. O ensino de julgamento e tomada de decisão nos cursos de graduação em Ciências Contábeis no Brasil. 133 f. Rio de Janeiro, 2012. Dissertação (Mestrado Executivo em Gestão Empresarial) - Fundação Getúlio Vargas, Rio de Janeiro, 2012.

MCCLELLAND, D. C. Testing for competence rather than for "intelligence". American Psychologist, Washington, v. 28, n. 1, p. 1, 1973.

MCLAGAN, P. A. Models for HRD practice. Training and Development Journal, United Kingdon, v. 43, n. 9, p. 49-60, 1989.

MINTZ, S. M. Ethics, professional judgment, and principles-based decision making under IFRS. The CPA Journal, New York, v. 81, n. 1, p. 68, 2011.

NICKERSON, R. S. Confirmation bias: A ubiquitous phenomenon in many guises. Review of general psychology, v. 2, n. 2, p. 175-220, 1998.

RAMOS, C. Instrumentos financeiros: introdução às regras de mensuração, contabilização e divulgação. São Paulo: César Ramos \& Cia Ltda., 2014.

RICHARDSON, R. J. Pesquisa social: métodos e técnicas. 3. ed. São Paulo: Atlas S.A, 2007.

SCHMUTTE, J.; DUNCAN, J. R. Professional judgment: a model for accounting and auditing decisions. The CPA Journal, New York, v. 79, n. 9, p. 32, 2009.

SIMON, H. A. A behavioral nodel of rational choice. The Quarterly Journal of Economics, Cambridge, v. 69, n. 1, p. 99-118, 1955.

STERNBERG, R. J.; OSÓRIO, M. R. B. Psicologia cognitiva. Porto Alegre: Artmed, 2000.

THALER, R. H. Mental accounting matters. Journal of Behavioral Decision Making, New Jersey, v. 12, n. 3, p. 183-206, 1999. 